\title{
Work-Related Accident Prevention in Norwegian Road and Maritime Transport: Examining the Influence of Different Sector Rules
}

\author{
Tor-Olav Nævestad *, Beate Elvebakk and Karen Ranestad
}

check for updates

Citation: Nævestad, T.-O.; Elvebakk, B.; Ranestad, K. Work-Related Accident Prevention in Norwegian Road and Maritime Transport: Examining the Influence of Different Sector Rules. Infrastructures 2021, 6 , 72. https://doi.org/10.3390/ infrastructures6050072

\section{Academic Editors:}

Krzysztof Goniewicz, Robert Czerski and Marek Kustra

Received: 13 March 2021

Accepted: 6 May 2021

Published: 11 May 2021

Publisher's Note: MDPI stays neutral with regard to jurisdictional claims in published maps and institutional affiliations.

Copyright: (C) 2021 by the authors. Licensee MDPI, Basel, Switzerland. This article is an open access article distributed under the terms and conditions of the Creative Commons Attribution (CC BY) license (https:/ / creativecommons.org/licenses/by/ $4.0 /)$.
Institute of Transport Economics, Gaustadalléen 21, NO-0349 Oslo, Norway; beateelv@oslomet.no (B.E.); Karen.Ranestad@banenor.no (K.R.)

* Correspondence: ton@toi.no; Tel.: +47-2257-3800; Fax: +47-2260-9200
Abstract: About $36 \%$ of fatal road accidents in Norway involve at least one driver who is "at work". It has been argued that the implementation of rules clearly defining the responsibility of road transport companies to prevent work related accidents, by implementing safety management systems (SMS), could lead to increased safety. In the present study we tested the validity of this suggestion, by examining the influence of different sector rules on work-related accident prevention in Norwegian road and maritime transport. In contrast to the road sector, the maritime sector has had rules requiring SMS for over 20 years, clearly defining the shipping companies responsibility for prevention of work-related accidents. The aims of the study were to: (1) examine how the different sector rules influence perceptions of whether the responsibility to prevent work-related accidents is clearly defined in each sector; and (2) compare respondents' perceptions of the quality of their sectors' efforts to prevent work-related accidents, and factors influencing this. The study was based on a small-scale survey $(\mathrm{N}=112)$ and qualitative interviews with sector experts $(\mathrm{N}=17)$ from companies, authorities, and NGOs in the road and the maritime sectors. Results indicate that respondents in the maritime sector perceive the responsibility to prevent work-related accidents as far more clearly defined, and they rate their sector's efforts to prevent accidents as higher than respondents in road. Multivariate analyses indicate that this is related to the scope of safety regulations in the sectors studied, controlled for several important framework conditions. Based on the results, we conclude that the implementation of SMS rules focused on transport companies' responsibility to prevent work-related accidents could improve safety in the road sector. However, due to barriers to SMS implementation in the road sector, we suggest starting with a simplified version of SMS.

Keywords: safety management; regulation; transport; road; maritime

\section{Introduction}

\subsection{Background}

A study from Norway indicates that $36 \%$ of fatal road accidents involved at least one driver who was "at work" at the time of the accident [1]. An average of 1.490 people is injured (lightly or seriously) in these accidents and the majority ( $81 \%$ ) of these people are other road users [2]. This means that measures to improve transport safety in companies with working drivers will not only reduce the number of injuries among drivers at work, but particularly among other road users.

Although there are relatively few systematic studies in this area, research indicates that implementation of safety management systems (SMS) can lead to increased road safety. A comprehensive literature review indicates that the implementation of SMS is related to positive safety outcomes [3]. SMS is legally required as a tool for implementing safety culture in several high-risk industries, e.g., the nuclear sector [4], aviation [5,6], and oil and gas (e.g., [7]). 
SMS denote the formal aspects of safety in organizations ("how things should be done"). The informal aspects of safety management generally refer to safety culture ("how things are actually done"), which can be defined as shared and safety relevant ways of thinking or acting that are (re)created through the joint negotiation of people in social settings [8]. The development of a positive safety culture is a formal aim and justification of SMS in the maritime sector [9], in aviation [5] in rail [10], and also in the voluntary ISO:39001 standard in the road sector. Thus, it is believed that the development of formal procedures ("how things should be done") will influence informal practices ("how things actually are done") [11]. Studies also indicate positive effects of SMS on safety culture in aviation [12], in the maritime sector [13] and in rail [14,15].

SMS typically comprise formal routines and measures enabling the organization to work systematically with safety, e.g., by establishing formal safety policies and goals, establishing key roles and responsibilities, systematically collecting information about incidents and hazards, developing countermeasures, monitoring the effects of these, and adjusting measures if necessary (cf. [3]). Moreover, SMS clearly define companies' responsibility to prevent work-related accidents, through the implementation of such formal measures [16].

Studies of SMS implementation from the road sector report of reductions in accidents and incidents, improved safety culture and improved road safety behaviours [17-20]. In addition, previous studies show that hauliers transporting dangerous goods (road tanker) by road have a $75 \%$ lower risk of accidents than other goods transport companies [21]. These companies also work more systematically with SMS and safety culture than other hauliers [22].

Despite the promising safety outcomes of SMS in road and other sectors, Norwegian research from the road sector indicates that neither transport companies nor authorities focus sufficiently well on the importance of SMS and the organizational responsibility for safety [23]. Similar tendencies have been found in research from other countries, indicating that work-related road safety traditionally has been managed using single driver-focused measures, and not SMS and safety culture (e.g., [22,24]).

The tendency to focus on the driver instead of the organization in efforts to prevent accidents has been related to the legal rules governing work-related accident prevention in the road sector. Interviewees in a previous Norwegian study reported that authorities largely focus on the Road Traffic Act, which places the main responsibility for safety on the driver, in their enforcement of the safety of drivers at work [23]. This means that drivers at work in practice are treated as private drivers, although the employers of the former have a legal responsibility for their safety through the Working Environment Act. The interviewees also stated that very few employers recognize this responsibility, e.g., by implementing SMS. Based on this, sector experts in the study of Nævestad and Phillips [23] suggested that the road sector should learn from other sectors, which focuses on the organizational responsibility to prevent work related accidents, e.g., by implementing SMS. The same suggestion is discussed in an ITF roundtable session about SMS in transport [22].

In the present study we test the validity of this suggestion, by examining the influence of different sector rules on work-related accident prevention in Norwegian road and maritime transport. More specifically, we examine whether the maritime sector performs better on the prevention of work-related accidents because of the different rules regulating safety in the two sectors. We have chosen to compare road with the maritime sector, as the maritime sector has had rules requiring SMS for over 20 years, clearly focusing on the organizational responsibility to prevent accidents. In contrast, formal SMSs for companies in the road sector are voluntary so far (e.g., ISO:39001).

\subsection{Aims}

The aims of the study are to: (1) examine how the different sector rules influence perceptions of whether the responsibility to prevent work-related accidents is clearly defined in road and the maritime sector; and (2) compare respondents' perceptions of the quality of their sectors' efforts to prevent work-related accidents, and factors influencing this. 


\section{Theoretical Approach and Previous Research}

\subsection{The Rules Governing Safety and SMS in the Road and Maritime Sector}

SMS was legally required in the maritime sector in 1998 through the International Safety Management (ISM) code of the International Maritime Organization (IMO), which requires SMS in all commercial ships over 500 GT. The ISM code was introduced after several severe maritime accidents were found to be caused by human error and insufficient SMS. One of the main purposes of the ISM-code is to firmly define the shipping company and the ship master's responsibility for the management of safety and the environment, through the implementation of ISM compliant SMS [25]. According to the ISM code, an SMS should include, for instance: (1) a safety and environmental protection policy; (2) procedures to ensure the safe operation of ships; and (3) defined lines of communication between shore and shipboard personnel $[9,26]$. The ISM code is implemented as a provision to the Norwegian Ship Safety and Security Act [27]. Actors in the sector have considered this act to clarify responsibilities, through increasing the focus on shipping companies' responsibility for accident prevention [28].

International research indicates low SMS implementation among companies in the road sector, as this is not legally required [22]. Some of the large companies have, however, adopted advanced SMS practices, particularly companies transporting dangerous goods including oil and chemical products [22]. The closest one comes to overarching legislation for SMS in the road sector is the EU Framework Directive on Safety and Health at Work (Directive 89/391/EEC) and corresponding national legislation that sets out the need for employers of drivers at work to manage accident risks associated with road users, trips, and vehicles [16]. The corresponding national legislation in Norway is the Working Environment Act (WEA). However, although employers of drivers at work in Norway have a legal responsibility for their safety through the WEA, very few employers recognize this responsibility, e.g., by implementing SMS [23]. The most important legislation regulating road safety in Norway is the Road Traffic Act (RTA), which applies to all road users, and which places the main responsibility for safety on the driver. Nævestad and Phillips [23] report that authorities tend to enforce the RTA more often than WEA when dealing with drivers at work. This indicates a less clear responsibility for work-related accident prevention in the road sector, and a more driver-centered approach, which also is found in international approaches [24]. The most well-known SMS approach in the road sector is the ISO:39001 traffic safety standard. This is, however, voluntary. The standard is often described as a management system for traffic safety and a tool for building safety culture. An explicit goal of this standard is to create a positive safety culture by implementing SMS. Only eight companies had, however, implemented this standard in Norway in 2018.

\subsection{Safety Outcomes of SMS}

Although there are few studies comparing safety culture and safety outcomes across transport sectors, previous research indicates more focus on safety management systems, more advanced safety cultures and better safety outcomes in aviation, rail, and the maritime sector, compared with the road sector (cf. $[22,29,30]$. This can be explained by the fact that companies in the road sector do not have the same legal requirements for safety management systems as in aviation (IATA 2019), the maritime sector [13], and railways [10]. In these sectors, requirements are set for systems aiming to facilitate key aspects of safety culture; e.g., a safety culture including reporting, justice, and learning. These requirements are often cited to explain why companies in aviation [31,32], the maritime sector [13], and rail transport [14] perform better than the road sector on safety. Several studies find relationships between implementation of SMS, or SMS elements, and positive safety culture and safety outcomes in aviation [31,32], in rail [15], in the maritime sector [13] and in the road sector [17].

Finally, it should also be noted that identifying the safety outcomes of SMS is a challenging methodological issue. There are few robust evaluations of this (i.e., with prepost measurements, control, and test groups). Additionally, studies have not yet managed 
to study the separate effects of the different elements in SMS. There are also several different definitions of SMS. It should also be noted that relationships are complex, and that it may be difficult to discern between elements of safety culture interventions and elements in SMS interventions. In his systematic review of the effects of safety management systems in the transport sector, Thomas [3] concludes that, despite little research in the field, there seems to be a relationship between SMS and objective safety outcomes (behavior and accidents). Although there is no agreement on which components of safety management systems contribute most to safety, Thomas [3] concludes that the following two factors are the most important: management commitment to safety and safety communication. Additionally, there are few studies comparing safety management across sectors as we do in the present study. Making such comparisons may be difficult, as other framework conditions (in addition to SMS rules) are also important in explaining different safety levels between sectors (cf. [29]). Such framework conditions may be, e.g., competition, business structure (number and size of companies), economy, and customer focus on safety. We return to this issue.

\subsection{Mechanisms through Which SMS May Influence Safety Outcomes}

SMS may lead to positive safety outcomes through at least two mechanisms. The first is that SMS provides a systematic way of managing organizational safety, and that it clearly places responsibility for this process in the company. The philosophy that the ISM code is based on is total quality management, highlighting continuous improvement through management commitment and personnel empowerment (Lappalainen 2008 in [29]). The process of continuous improvement follows Deming's circle ('plan-do-check-act') [29]. Implementing an SMS involves analyzing the safety status and setting goals (plan), implementing measures to fulfil the goals (do), developing indicators to measure goal attainment (check), and adjusting the measures if necessary (act).

The second mechanism through which SMS may produce positive safety outcomes is through the development of a positive safety culture. As noted, this is the explicit motivation for most SMS legislation, hypothesizing that the development of formal procedures ("how things should be done"), will influence informal practices ("how things actually are done") [11]. Implementing an SMS largely concerns implementing certain routines and ways of doing things in the organization, e.g., carrying out risk assessments, documenting the process, developing procedures, and training new employees etc. $[13,16,17]$. The implementation of such activities can lead to improved safety culture, especially if it is followed by increased focus on safety among managers and employees in the organization.

\subsection{Potential Barriers to SMS Implementaion}

Contrary to the hypothesized relationship between SMS and safety culture that is described above, several studies report discrepancies between formal and informal aspects of safety in organizations $[26,33,34]$. Thus, it seems that a positive safety culture does not necessarily follow from SMS implementation. This can be explained by, e.g., SMS that are poorly adapted to the companies in question, by referring to the nature of the working activities, to the competence of the personnel, etc. [26,34]. These factors can also be related to the size and maturity of companies, etc. The report from the ITF [22] roundtable on SMS in transport mentions several such potential barriers to successful SMS implementation in the road sector, for example: (1) there is no international regulatory or standard setting body in road transport of the kind responsible for aviation (ICAO) or maritime transport (IMO); (2) there is a large share of non-professional road users; (3) there are many small companies; (4) high proportion of owner-drivers; and (5) low organizational maturity, indicated, e.g., by low degree of reporting of incidents and little systematic focus and follow up of indicators measuring performance [22]. These factors may challenge the possibilities to implement SMS and continuous improvement (PDCA) in companies in the road sector. 


\subsection{Hypotheses}

As the SMS rules in the maritime sector firmly places the responsibility for safety on the shipping company and the shipmaster, we hypothesize that respondents in the maritime sector have a stronger perception that the responsibility for accident prevention is clearly defined in their sector regulations (Hypothesis 1). Moreover, based on this we also expect respondents in the maritime sector to rate their efforts to prevent work related accidents as higher than respondents in the road sector (Hypothesis 2). Finally, we expect that respondents in the maritime sector rate SMS as more important for the safety level in their sector than respondents in the road sector (Hypothesis 3).

\section{Methods}

We have used two methods to fulfil the study aims. The first method is semi structured qualitative interviews with 17 sector experts. We conducted these to get rich information, based on the interviewees' experiences and viewpoints, and also as a background to the development of the quantitative survey. The qualitative interviews resulted in textual data that we used to complement the numerical data from the survey. The use of quantitative survey data is the second method, and this is based on 112 respondents. We use this to make statistical comparisons between the answers of respondents from the two sectors.

\subsection{Interviews}

We have conducted qualitative interviews with 17 sector experts to gain knowledge on the aims of the study. Interviewees were selected from transport companies, the Labour Inspection Authority, the Public Roads Administration, including personnel from the Accident Analysis Groups, the Norwegian Maritime Directorate, the Accident Investigation Board, the Norwegian Coastal Administration, and other relevant actors. The interviews were conducted in 2016 and 2017. The interviews were conducted face-to-face and by telephone. The interviews generally lasted for between one and one and a half hours. We used a semi structured interview guide, and the themes and questions in the guide focused on the aims of the study.

The interview guide focused on the following themes:

(1) Background information about the interviewees' work;

(2) Registration and overview of work-related accidents in the sector of the interviewee;

(3) Registration and overview of work-related risk factors in the sector of the interviewee;

(4) Views on responsibilities related to the occurrence and prevention of work-related accidents;

(5) Current, past (and potential future) measures aiming to prevent work-related accidents;

(6) Views on efforts to prevent work-related accidents in companies.

The purpose of the interviews was to give us more insight into the interviewees' understanding of their organizations' knowledge and information sources about work-related accidents, views on risk factors and thoughts on roles and responsibilities. We collected this information to be able to conduct rich comparisons between the studied sectors. Interviewees were encouraged to "think out loud" and they were assured that the purpose of the interview was to provide us with nuanced viewpoints and thoughts that we cannot collect by means of survey methods. Although the themes in the interviews were fairly similar to those in the survey, the qualitative interviews involved open ended questions which allowed the interviewees to elaborate freely when answering.

\subsection{Survey}

\subsubsection{Recruitment of Respondents and Sample Characteristics}

A small-scale web-based survey was distributed to representatives from government agencies, NGOs, and personnel in transport companies in the two sectors. Relevant representatives from government agencies were identified with assistance from the project's reference group. The survey was sent to relevant persons in the Transport Accident Inves- 
tigation Board Norway, the Ministry of Transport and Communications, the Norwegian Public Road Authority, the Norwegian Maritime Authority, the Norwegian Labour Inspection Authority, and the Norwegian Public Roads Administration's Accident Analysis Groups. The survey was also sent to transport companies in the studied sectors, and they were asked to distribute the survey among elected safety officials and trade union representatives. Thus, the survey includes what we may term sector experts, with good knowledge resulting from efforts to prevent work-related accidents within the sectors. Table 1 shows the distribution of sector experts in the different sectors, by type of organization.

Table 1. Distribution of sector experts in the studied sectors, by type of organization.

\begin{tabular}{ccccccr}
\hline Sector & Directorate & Inspectorate & $\begin{array}{c}\text { Investigation } \\
\text { Board }\end{array}$ & $\begin{array}{c}\text { Transport } \\
\text { Company }\end{array}$ & Other & Total \\
\hline Road & $14 \%$ & $20 \%$ & $6 \%$ & $55 \%$ & $6 \%$ & 66 \\
\hline Maritime & $30 \%$ & $9 \%$ & $0 \%$ & $54 \%$ & $5 \%$ & $6 \%$ \\
\hline Total & $21 \%$ & $15 \%$ & $4 \%$ & $54 \%$ & 112 \\
\hline
\end{tabular}

There were 112 individual respondents: 59\% $(\mathrm{N}=66)$ from the road sector and $41 \%$ $(\mathrm{N}=46)$ from the maritime sector. The respondents from transport companies in both sectors were largely recruited from two unions: one union from the road sector including drivers and one union from the maritime sector which largely includes ship navigators. Thus, although both groups of union members are transport operators, the operators from the maritime sector rank higher in the organizational hierarchy than those in the road sector. While the method of distribution makes it impossible to calculate the response rate, it is obvious that it has been very low. This, in addition to the limited number of responses, means that results must be treated with considerable caution.

\subsubsection{Survey Themes}

The survey contains seven different themes:

(1) Background questions, e.g., sector, type of organization, position;

(2) Views on risk factors related to work-related accidents;

(3) Questions on why the number of work-related accidents has been reduced in recent years, whether respondents have a good overview of the occurrence of work-related accidents and causes, sources of information, and whether companies report all accidents;

(4) Questions on the responsibility for the prevention of work-related accidents and whether responsibility is clearly defined in current legislations;

(5) Rating of respondents' organizations efforts to prevent work-related accidents, views on the safety rules in the sectors, and questions about the significance of framework conditions for safety.

\subsubsection{Quantitative Analysis}

Regression analysis. We have performed two regression analyzes. The first was conducted to assess the conditions explaining variation in the respondents' answer to the question: "Is responsibility for accident prevention sufficiently clearly defined in current regulations in the sector?" The second was to assess respondents' agreement with the statement: "How would you rate your organization's efforts to prevent work-related accidents?". We used logistic regression in the first analysis, as the dependent variable was made dichotomous (1: Yes, 2: No/do not know). We used linear regression in the second analysis, since the dependent variables are continuous. The regression analyzes show the effects of the independent variables that we include on the two dependent variables, controlled for the other variables in the analysis. 


\section{Results}

\subsection{Is Responsibility for Accident Prevention Is Clearly Defined?}

The first aim of the study was to examine how the different sector rules influence perceptions of whether the responsibility to prevent work-related accidents is clearly defined in the maritime sector and in the road sector. As the SMS rules in the maritime sector firmly places the responsibility for safety on the shipping company and the shipmaster, we hypothesize that respondents in the maritime sector have a stronger perception that the responsibility for accident prevention is clearly defined in their sector regulations (Hypothesis 1).

In the survey, we asked whether responsibility for accident prevention was defined clearly enough in current regulations in the sector. The road sector stands out with a relatively low share of respondents stating that responsibility is defined clearly enough; $37 \%$ answered yes, compared with $78 \%$ in the maritime sector. The corresponding shares for no were $31 \%$ in road and $13 \%$ in the maritime sector. The road sector also had a larger percentage of respondents stating that they "do not know" (31\%), compared with $9 \%$ in the maritime sector. Differences between the sectors were statistically significant at the $1 \%$ level.

Respondents from the road sector who gave reasons for their answers referred to the relationship between drivers and their employer organizations and/or their customers. They referred to stress or pressure as a result of short deadlines, and the fact that drivers are held responsible even though they are not the ones who define the route and the time frame. In this manner, they underlined that transport buyers also indirectly influence the safety of transport assignments. Moreover, they also pointed to drivers' legal responsibilities as a problem, as they may provide an opportunity for managers or customers to ignore their actual influence and liability. This indicates a discrepancy between the legal responsibilities of drivers and the practical responsibilities of, e.g., transport buyers in the road sector.

The majority of interviewees from the road sector thought employers should take more responsibility for their employees' behaviour and safety in traffic, as part of their HSE work. Specifically, they believed that work assignments should be based on risk assessments, including an analysis of the road and conditions, and employers should develop safetypromoting routines, procedures and guidelines. It was noted that many businesses fail to fulfil these requirements today. Road transport differs from most professional sectors in that individual drivers usually carry the entire responsibility for safety, and some of the interviewees stated that the companies have-or should take on - the overarching responsibility for the interplay between the various elements and actors involved in road traffic. Some of the interviewees from the road sector believed that relations of responsibility in this area should be more clearly defined, especially HSE-requirements or safety standards. Others found responsibilities to be well-defined in theory, but they said that the practical follow-up was inconsistent. The Working Environment Act gives employers a wide-ranging responsibility for their workers' safety, but interviewees noted that this is rarely enforced. The Road Traffic Act-which places all responsibility with the driver-is enforced through controls and in police investigations following accidents, but the responsibility of the firms is not enforced to the same degree. So while the law divides responsibility between different actors, this is not the case in practice.

Interviewees in the maritime sector underline that safety in the maritime sector is circumscribed by the International Maritime Organisation (IMO). This is a specialized agency of the United Nations whose primary purpose is to develop and maintain a comprehensive regulatory framework for shipping. The Norwegian Maritime Authority (NMA) is the government agency responsible for life, health, and working conditions for Norwegianregistered ships and ships at Norwegian ports and is also in charge of active safety work, such as inspections regulated by international law. The Norwegian Coastal Administration is responsible for maritime infrastructure and maritime safety services, while the Labour Inspection Agency is responsible for working conditions in ports. Safety in the maritime 
sector in Norway is regulated through the Ship Safety and Security Act, which came into existence in 2007. According to this act:

"The company has an overall duty to see to that the construction and operation of the ship is in accordance with the rules laid down in or pursuant to this Act, including that the master and other persons working on board comply with the legislation". (§6)

Section 58 in this act relates to the establishment of SMS (as required by the ISM code).

\subsection{Respondents' Assessment of the Quality of Their Sectors' Efforts}

\subsubsection{Ratings of the Sector's Efforts to Prevent Work-Related Accidents}

The second aim of the study was to examine respondents' perceptions of the quality of their sectors' efforts to prevent work-related accidents, and factors influencing this. As responsibilities for the prevention of work-related accidents are more clearly in the maritime sector, we expected respondents in the maritime sector to rate their efforts to prevent work related accidents as higher than respondents in the road sector (Hypothesis 2). This is compared in Figure 1, where we show results for the question: "How would you rate your own organizations' work with work-related accidents on a scale from 1 (= very deficient) to 7 (= very good).

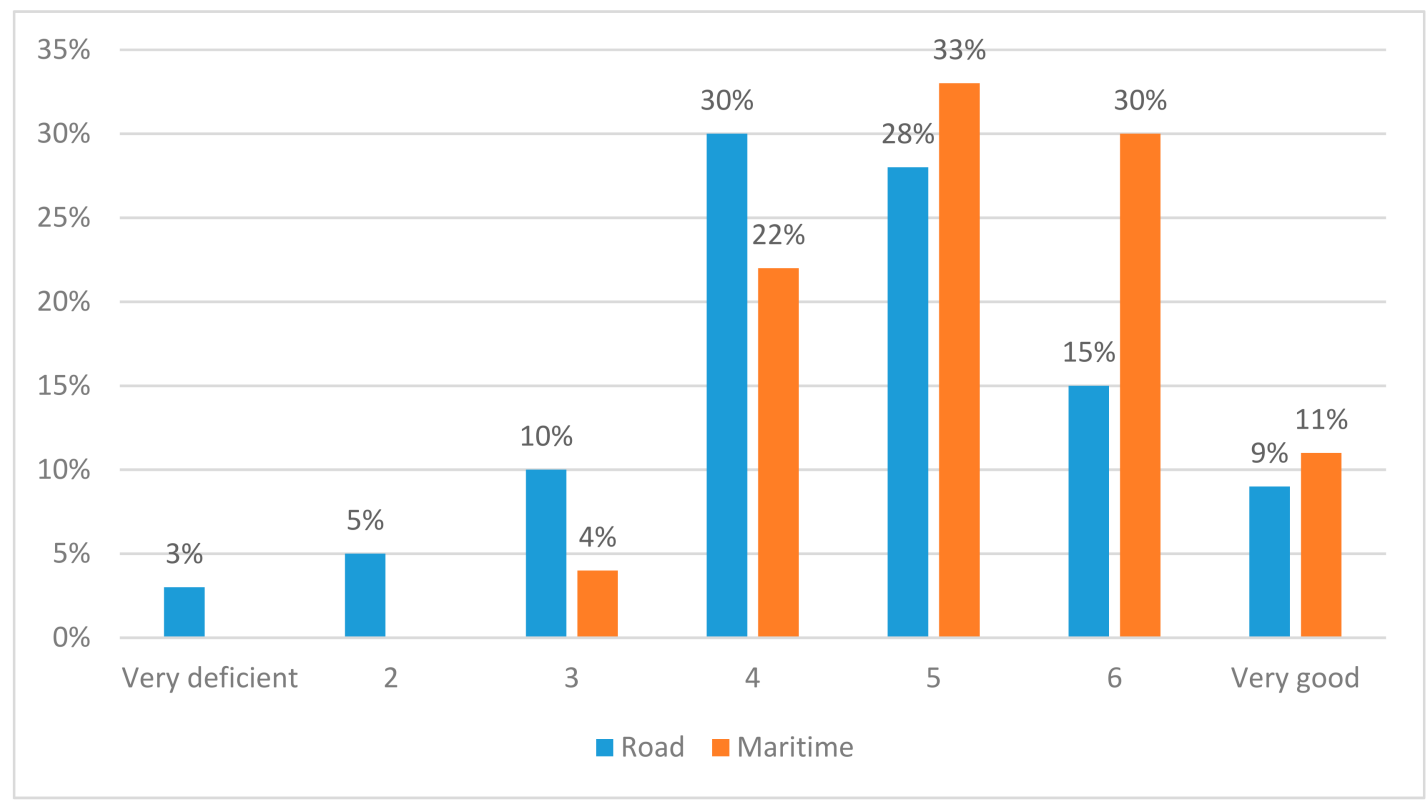

Figure 1. How would you rate your own organizations' work with work-related accidents on a scale from 1 (= very deficient) to 7 (= very good) by sector. Shares from $\operatorname{Road}(\mathrm{N}=66)$ and the maritime sector $(\mathrm{N}=46)$.

Figure 1 indicates that respondents from the road sector rate their own efforts to prevent work-related accidents as lower than respondents from the maritime sector. If we assume that scores ranging from 5-6 means "good", we see that $74 \%$ of the respondents in the maritime sector rate their own organization's work with work-related accidents as good, compared to $52 \%$ in the road sector. Correspondingly, $18 \%$ rate their organization's efforts as deficient in the road sector, compared to $4 \%$ in the maritime sector. The sector experts that we interviewed often referred to the rules governing safety in their sector and the enforcement of these rules when discussing their sectors' and organizations' efforts to prevent work-related accidents. Interviewees in the road sector referred, e.g., to the lacking enforcement of the Working Environment Act, while interviewees in the maritime sector referred to the SMS requirements of the ISM-code. 


\subsubsection{Respondents' Rating of the Safety Level and Framework Conditions}

Respondents were also asked to rate the safety level in their own sector compared to that of international commercial aviation on several key aspects. Respondents were asked: "Imagine a scale from 1 to 10 indicating the level of safety, where 10 corresponds to the level of safety in international commercial aviation", "How would you rate the level of safety in your sector?" We also asked three additional questions, worded in the same manner, focusing on authorities' focus on safety, customer focus on safety and scope of safety regulations. The results are indicated in Figure 2.

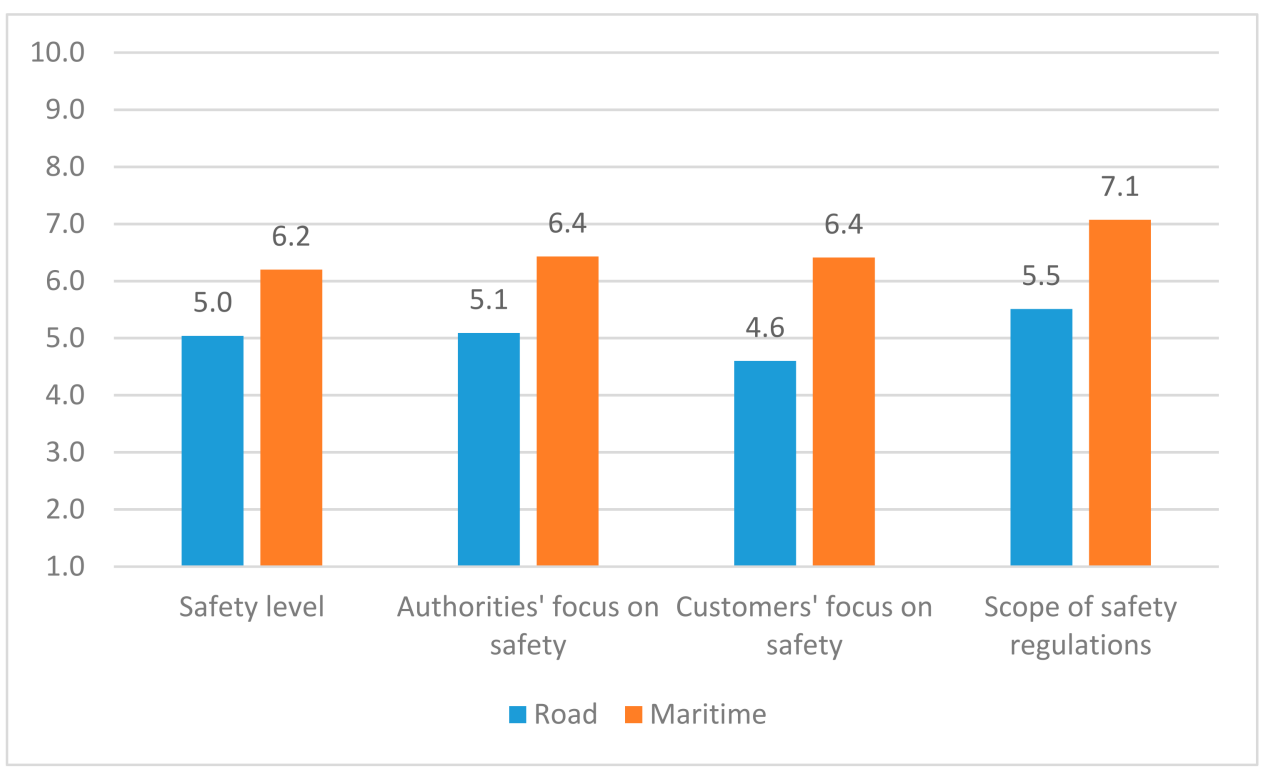

Figure 2. Results for four questions based on the formulation: "Imagine a scale from 1 to 10 indicating the level of safety, where 10 corresponds to the level of safety in international commercial aviation", "How would you rate your sector?" Similar questions were asked for: authorities' focus on safety, customer focus on safety and scope of safety regulations. Respondents from road $(\mathrm{N}=66)$ and Maritime $(\mathrm{N}=46)$.

Results indicate a general pattern; respondents from the maritime sector rate the safety level in their sector as higher than respondents in the road sector. All differences were statistically significant at the $1 \%$ level. The comparisons were "anchored" in an absolute reference point (i.e., the commonly known standard of international commercial aviation), as previous research has indicated that comparisons across contexts may be difficult, as respondents' assessments are relative, based on the different reference points and expectations in their respective sectors [35].

\subsubsection{Respondents' Ratings of Factors Influencing the Safety Level in Their Sector}

We expect that respondents in the maritime sector rate SMS as more important for the safety level in their sector than respondents in the road sector (Hypothesis 3). In a previous study, we found a strong decline in the number of people injured in work-related accidents in both the road- and the maritime sector [2]. Based on this, we asked respondents about the following: "The number of work-related accidents in your sector has fallen sharply in recent years. What do you think are the reasons for this decline?" Seven answer alternatives were provided (cf. Figure 3). 


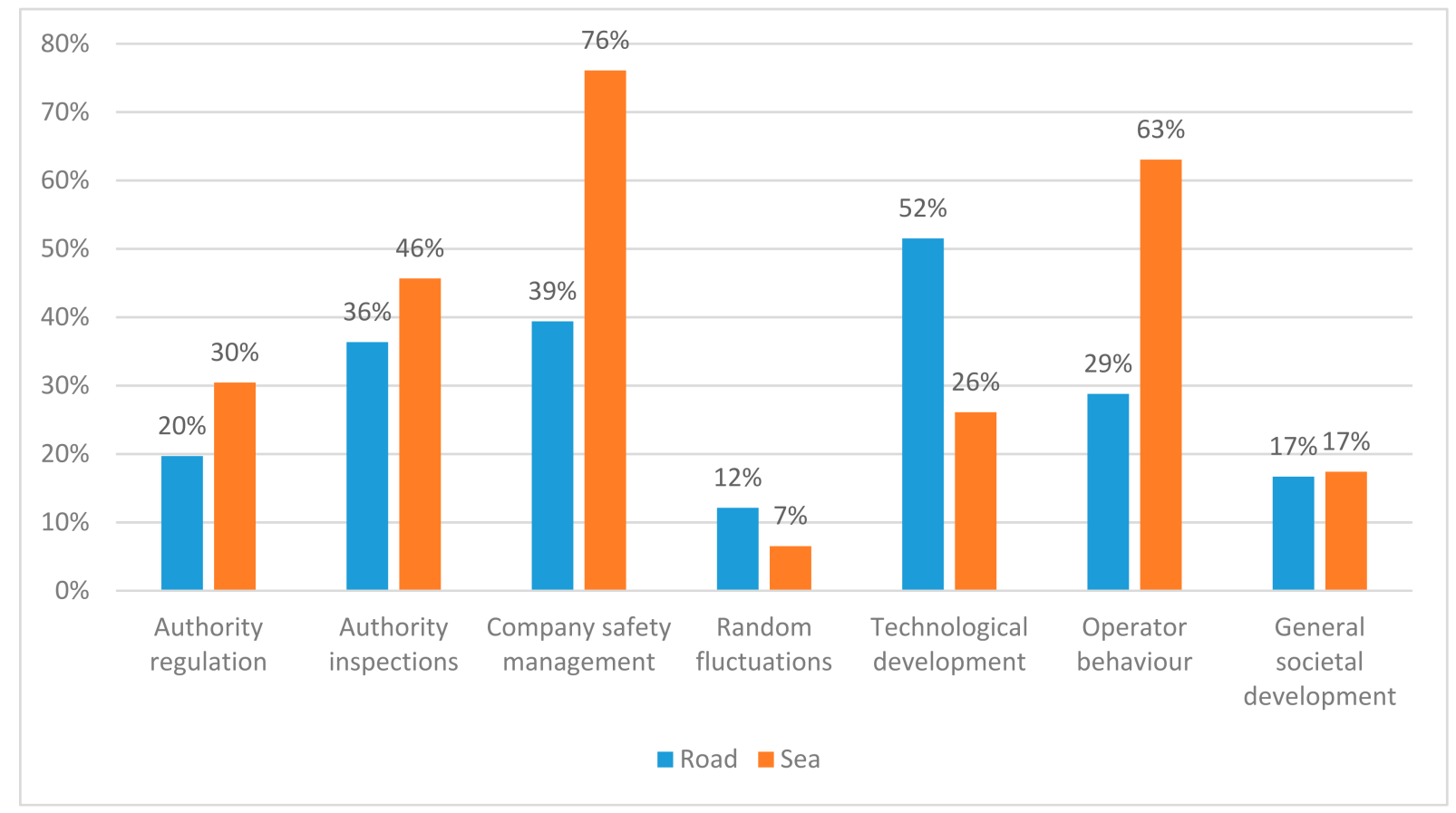

Figure 3. Results for respondents answer to the question: "The number of work-related accidents in your sector has fallen sharply in recent years. What do you think are the reasons for this decline?" Seven answer alternatives were provided. Respondents from road $(\mathrm{N}=66)$ and Maritime $(\mathrm{N}=46)$.

Figure 3 indicates that the most important answer provided by respondents from the road sector is technological development; half of the respondents from road answered this, which is twice as much as in the maritime sector. The most prevalent answer provided by respondents from the maritime sector is companies' safety management. This is in accordance with Hypothesis 3, and we can probably attribute this result to the focus on SMS in the maritime sector. The share answering "company safety management" in the maritime sector $(76 \%)$ is nearly twice as high as that in the road sector (39\%). This result is not surprising, given the fact that SMS is not mandatory in the road sector.

In the interviews, we also asked the sector experts to point to the most important measures against work-related transport accidents that have been introduced in recent years. Interviewees in the maritime sector pointed to the SMS requirements of the ISM code:

"It is the ISM safety management systems that have been introduced. We think they work, based on the decline in work accident rates, but the background is a bit unclear. But I believe that the [SMS] requirements have led to a certain enlightenment in the shipping companies about how to implement measures, an increased focus."

Another interviewee stated, in line with this, that the focus on the human factors and safety management has increased because of the SMS-requirements of the ISM code.

\subsection{Multivariate Analyses}

4.3.1. Which Factors Influence Respondents' Perception That Responsibility for the Prevention of Work-Related Accidents Is Clearly Defined in Their Sector?

In Table 2, we examine factors influencing respondents' perception whether responsibility for the prevention of work-related accidents is clearly defined in their sector 
Table 2. Logistic regression. Dependent variable: "Is the responsibility for the prevention of workrelated accidents sufficiently clearly defined in your sector? $(0=$ Yes, $1=$ No/don't know $)$. B values.

\begin{tabular}{cccc}
\hline Variable & Mod. 1 & Mod. 2 & Mod. 3 \\
\hline $\begin{array}{c}\text { Type of org. } \\
(\text { Company }=0 \text {, Other } \\
=1 \text { ) }\end{array}$ & $-1.147^{* * *}$ & $-1.419^{* * *}$ & $-1.616^{* * *}$ \\
$\begin{array}{c}\text { Sector (Maritime =0, } \\
\text { Road }=1 \text {, }) \\
\begin{array}{c}\text { Scope of safety } \\
\text { regulations } \\
\text { Adjusted R2 }\end{array}\end{array}$ & $2.044^{* * *}$ & $1.791^{* * *}$ \\
${ }^{*} p<0.1^{* *} p<0.05^{* * *} p<0.01$. & 0.100 & & $-0.267^{* *}$ \\
\hline
\end{tabular}

The first main result is that we see a positive and significant relationship between the road sector and disagreement with the statement that the responsibility for accident prevention is clearly defined. This is as expected, based on the bivariate results, however, in this analysis we also control for type of organization and the scope of safety regulations in the sector.

The second main result is that type of organization contributes negatively and significantly. This means that respondents from companies tend to assess that responsibilities for accident prevention is more clearly defined than respondents from other types of organizations, e.g., authorities. This could have been due to SMS rules applying to companies in the maritime sector, but we control for sector.

Third, results indicate a negative relationship between the scope of safety regulations and the dependent variable. This indicates that respondents who are subjected to comprehensive safety regulations (i.e., in the maritime sector) are more likely to perceive that the responsibility for prevention of work-related accidents are clearly defined.

The Nagelkerke R value is 0.376 , which means that the model explains $38 \%$ of the variation in the dependent variable.

4.3.2. Which Factors Influence Respondents' Ratings of Their Organizations' Efforts to Prevent Work-Related Accidents?

In Table 3, we examine factors influencing respondents' ratings of their organizations' efforts to prevent work-related accidents.

Table 3. Linear regression. Dependent variable: “How would you rate your organization's efforts to prevent work-related accidents?" (Min =1, Max =7) Standardized beta coefficients.

\begin{tabular}{|c|c|c|c|c|c|c|c|}
\hline Variable & Mod. 1 & Mod. 2 & Mod. 3 & Mod. 4 & Mod. 5 & Mod. 6 & Mod. 7 \\
\hline $\begin{array}{l}\text { Type of org. (Oth. }=1 \\
\text { Company }=2)\end{array}$ & 0.170 * & $0.171 *$ & 0.076 & 0.163 & 0.141 & 0.145 & 0.138 \\
\hline $\begin{array}{l}\text { Sector }(\text { Road }=1, \\
\text { Maritime }=2)\end{array}$ & & $0.239 * *$ & $0.189 * *$ & 0.106 & 0.040 & 0.036 & 0.050 \\
\hline $\begin{array}{c}\text { Companies report all } \\
\text { incidents }\end{array}$ & & & $0.246^{* *}$ & 0.187 * & 0.143 & 0.141 & 0.126 \\
\hline $\begin{array}{c}\text { Responsibility is clearly } \\
\text { defined (Yes }=1, \\
\text { No/don't know }=2)\end{array}$ & & & & $-0.232^{* *}$ & -0.166 & -0.171 & -0.152 \\
\hline $\begin{array}{l}\text { Scope of safety } \\
\text { regulations }\end{array}$ & & & & & $0.307^{* * *}$ & $0.300 * * *$ & $0.289^{* * *}$ \\
\hline $\begin{array}{l}\text { Heavy competition } \\
\text { between comp. }\end{array}$ & & & & & & -0.026 & -0.029 \\
\hline $\begin{array}{l}\text { Safety more important } \\
\text { than price }\end{array}$ & & & & & & & 0.083 \\
\hline Adjusted R2 & 0.020 & 0.069 & 0.111 & 0.142 & 0.215 & 0.208 & 0.207 \\
\hline
\end{tabular}


The analyses in Table 3 indicates three main results. First, the most important result is that the variable "Scope of safety regulations" is the variable which has the strongest contribution to respondents' rating of their efforts to prevent work-related accidents. The positive beta coefficient indicates that respondents (in the maritime sector) who have the most comprehensive safety regulations, rate their efforts as better (than the road sector), also when we control for companies' reporting of accidents (which we have included as an indicator of sector safety culture) and framework conditions like competition between companies in the sector, and customers' focus on transport safety over price. The two latter framework conditions are measured by the following statements: "Heavy competition between companies is detrimental to safety in my sector" and "Safety is more important than price to customers". As illustrated in Figure 2, the maritime sector scores significantly higher than the road sector on the "Scope of safety regulations" variable. As noted, the full wording of the Scope of safety regulation variable is: "Imagine a scale from 1 to 10 indicating the scope of safety regulations, where 10 corresponds to the amount of safety regulations in international commercial aviation. How would you rate your sector?"

The second main result is that there is a close relationship between the scope of safety regulations variable and the variable "Responsibility for prevention of accidents is clearly defined". This variable contributed significantly and negatively in Model 4, indicating that lack of clearly defined responsibility for work-related accident prevention is related to lower ratings of your own organization's efforts to prevent such accidents. The clearly defined responsibility variable ceases, however, to contribute significantly in Model 5, when "scope of safety regulations" is included, indicating the close correlation between the two.

The third main result is that these variables are also closely related to sector. The sector variable contributes significantly in Models 2 and 3, indicating higher ratings of efforts to prevent work-related accidents in the maritime sector. The sector variable ceases, however, contribute significantly in Model 4, when the clearly defined responsibility variable is included, indicating the close relationship between the two, i.e., that this is more clearly defined in the maritime sector.

The fourth main result is that companies' reporting of incidents (i.e., sector safety culture), also is related to the scope of sector regulations, as the variable reporting of incidents ceases to contribute significantly when the variable scope of sector regulations is included in Model 5. The positive contribution indicates that reporting of incidents is related to higher ratings of efforts to prevent work-related accidents (and presumably a positive safety culture in the sector).

Finally, we see that neither customer focus on safety, nor heavy competition between companies influence respondents' rating of their efforts to present work-related accidents.

The Adjusted R value is 0.207 , which means that the model explains $21 \%$ of the variation in the dependent variable.

\section{Concluding Discussion}

\subsection{Is the Responsibility to Prevent Work-Related Accidents Clearly Defined?}

In contrast to the road sector, the maritime sector has had rules requiring SMS, clearly defining shipping companies' responsibilities for prevention of work-related accidents, for over 20 years. In the present study we tested the influence of different sector rules on work-related accident prevention in Norwegian road and maritime transport. The first aim of the study was to examine how the different sector rules influence perceptions of whether the responsibility to prevent work-related accidents is clearly defined in the maritime sector and in the road sector. As the SMS rules in the maritime sector firmly place the responsibility for safety on the shipping company and the shipmaster [25], we hypothesized that respondents in the maritime sector have a stronger perception that the responsibility for accident prevention is clearly defined in their sector regulations than respondents in the road sector (Hypothesis 1). 
Survey results supported Hypothesis 1; the road sector had a relatively low share of respondents agreeing that the responsibility for accident prevention was defined clearly enough in current regulations in the sector. The shares agreeing were $37 \%$ in the road sector, compared with 78\% in the maritime sector. Respondents from the road sector who gave reasons for their answers underlined that transport buyers also influence the safety of transport assignments. Moreover, in the road sector, interviewees stated that drivers at work usually carry the entire responsibility, as the Road Traffic Act, which places all responsibility with the driver, is enforced through controls and in police investigations. Interviewees pointed out that the Working Environment Act, which focuses on the responsibility of the employer and work-related risk factors is rarely enforced in practice in the road sector. The practical focus on the driver in the road sector is line with previous research from Norway [23] and research from other countries (e.g., [22,36]). Work-related road safety has traditionally been managed using single driver-focused measures, and not SMS and safety culture (e.g., [24]). In contrast, one of the main purposes of the ISM-code is to firmly define the shipping company and the ship master's responsibility for the management of safety and the environment $[25,26]$.

To sum up, results from the qualitative data indicate that respondents from the road sector found responsibility for work-related accident prevention unclear as: (1) the safety of drivers at work is regulated through at least two different rules; (2) only one of these is enforced in practice; and (3) in addition, other parties (e.g., transport buyers) also have a strong influence work-related road safety, but their influence is not recognised legally.

\subsection{The Quality of Efforts to Prevent Work-Related Accidents}

The second aim of the study was to compare respondents' perceptions of the quality of their sectors' efforts to prevent work-related accidents, and factors influencing this. Quantitative results indicate that respondents from the maritime sector rate their own organizations' efforts to prevent work-related accidents, and the safety level in their sector, as higher than respondents from the road sector. Moreover, respondents from the maritime sector also rate their sector authorities' focus on safety as higher, and the customer focus on safety in their sector as higher than respondents in the road sector. Respondents from the maritime sector also rate the scope of safety regulations as more comprehensive than respondents in road.

We conducted multivariate analyses to examine the factors influencing respondents' rating of their own organizations' efforts to prevent work-related accidents. The multivariate analyses generally indicate that respondents in the maritime sector rate their organizations' efforts to prevent work-related accidents as higher, as responsibility for accident prevention is more clearly defined, which in turn is related to the scope of the safety regulations. These results are in line with previous research, which indicates more focus on safety management systems, more advanced safety cultures and better safety outcomes in transport sectors with legal SMS requirements compared to the road sector (cf. $[22,29,30])$. Moreover, studies find relationships between SMS, or SMS elements and positive safety culture and safety outcomes in aviation [12,32], in rail [15], in the maritime sector [13], and in the road sector [17]. These results indicate the importance of sector rules requiring SMS for the prevention of work-related accidents. In accordance with this, the sector experts that we interviewed often referred to the rules governing safety in their sector and the enforcement of these rules when discussing their sectors' efforts to prevent work-related accidents.

It is difficult to compare transport sectors, as several framework conditions are likely to differ, in addition to the rules. In Figure 2, we saw, for instance, that customer focus on safety and authority focus on safety was rated higher among respondents in the maritime sector than in the road sector. In the multivariate analyses, we therefore controlled for such sector characteristics that could potentially represent confounding variables, e.g., competition between companies and customers' focus on safety versus price. In conclusion, 
we found that these variables do not influence respondents' rating of their efforts to present work-related accidents.

Additionally, we should ideally compare the risk of work-related accidents in each sector to compare the quality of efforts to prevent work-related accidents. It is however difficult to make such comparisons, as the measures of exposure differ in the sectors (e.g., kilometre in the road sector and days/hours at work in the maritime sector). This is an important issue for future research. Another interesting issue for future research is the influence of sector rules on safety culture in the sectors. Our multivariate analyses (Table 3) indicate relationships between sector rules, companies' reporting of incidents, which can be used as an indicator of sector safety culture (cf. [37]), and respondents rating of their organization's efforts to prevent work-related accidents. This is in line with previous research indicating that SMS rules may facilitate key aspects of safety culture; e.g., reporting, justice, and learning culture $[12,13,15]$.

\subsection{The Perceived Importance of SMS for Safety in the Maritime Sector}

The specific characteristic of the safety regulations that we focus on in the present study is the defined responsibility of companies for safety management through SMS rules, which are legally required in the maritime sector [13]. Based on this, our third hypothesis was that we expected that respondents in the maritime sector rate SMS as more important for the safety level in their sector than respondents in the road sector. We tested this hypothesis by asking respondents in the two sectors about the most important reasons for the decline in the number of work-related accidents in their sector, which has occurred in recent years [2]. The most important answer provided by respondents from the maritime sector was "companies' safety management" ( $76 \%$ in the maritime sector vs. $39 \%$ in the road sector). This is in accordance with Hypothesis 3, and we can probably attribute this result to the focus on SMS in the maritime sector. This result is not surprising, given the fact that SMS is mandatory in the maritime sector, but not in the road sector. In contrast, the most important answer provided by respondents from the road sector was technological development. The SMS requirements of the ISM code was also mentioned by interviewees in the maritime sector when asked to identify the most important measures against work-related accidents that has been introduced in recent years.

\subsection{Methodological Weaknesses and Issues for Future Research}

The main methodological weakness of the present study is the relatively small samples sizes of respondents from the road and maritime sectors that the quantitative survey is based on. The quantitative data is based on only 112 questionnaires in total. This is a small sample, which should be labelled a pilot study, especially since the groups of people working in transport companies were only 35 people in road transport and 25 people in maritime transport. The people in the transport companies are very important in a study like the current, because they directly encounter the issue of work-related accidents. Thus, we recommend that future studies further examining the themes that we discuss here include larger samples of people working in transport companies. This is required to establish robust conclusions. We have, however, not seen studies comparing sectors like we do in the present study, and it therefore provides an important contribution, although it is based on a small sample.

The small samples are due to the fact that recruitment of sector expert respondents was difficult, as we targeted very specialized personnel in the public authorities, NGOs, etc., and that there are relatively few of these specialized personnel in Norway. We made several efforts, e.g., by sending several reminders, to recruit relevant study participants.

The small samples may make comparisons across sectors difficult, in the sense that it may increase the risk of type II errors (false negative observations). This means that if we do not see significant differences between the studied sectors, it could potentially indicate that the groups are too small, rather than that the observed difference is unimportant. 
Another potential challenge related to the small sample is the issue of representativity. With the low number of respondents, it is reasonable to ask whether they actually are representative for their own sector. Unfortunately, it is impossible to calculate response rates, due to the method of survey distribution. When discussing the relatively small quantitative sample, it is important to note that we complement the quantitative data with rich qualitative interview data. Comparisons of quantitative data across sectors may be difficult, due to different reference points and baselines among the respondents. The qualitative data allows us to "control" for this in some sense, as we are able to get rich descriptions of these reference points and baselines, and comprehensive and complex accounts of the situation in each sector.

Since the quantitative and qualitative data was collected in 2016/17, it is important to discuss its current relevancy for policy and research. All in all, the main results of the present study can still be considered valid, as the rules regarding SMS and responsibility in road and the maritime sector have not changed since the data was collected. It is of course possible that some of the specific details provided in the qualitative interviews may have changed, but the legal contexts in the two sectors are still the same $[27,38,39]$, indicating that the main results regarding the comparisons of the sectors still provide important lessons for policy makers and researchers. Additionally, international research also indicates that the main conclusions regarding the comparisons of the sectors are valid for the situation in other countries (cf. [22,24,30,40], indicating the importance of our study.

\subsection{Policy Implications}

We may draw three main policy implications based on our study. The first is that our results indicate that the responsibility for the prevention of work-related accidents in the road sector is unclear in practice, and that this responsibility should be clarified. Both the Road Traffic Act and the Working Environment Act apply to drivers at work, but it seems that only the former is enforced in practice. The consequence is that drivers at work are treated as other private drivers, and that the potential of organizational safety management largely remains relatively unexploited in the road sector. As noted, about $36 \%$ of fatal road accidents involved at least one driver who was "at work" [1], and measures focusing on SMS and safety culture may lead to reductions in accident risk with up to $60 \%$ [40]. In a previous study, we estimated that between 7 and 56 deaths and severe injuries could have been avoided annually in Norway in the period 2007-2016, if more haulier companies had worked systematically with SMS and safety culture [41]. The potential is even greater if we focus on all drivers at work. It seems that this conclusion also applies to the international context (cf. [24]).

The second main policy implication of our study is that the responsibility should be clarified by also introducing SMS requirements in the road sector. The present study indicates that SMS rules are related to more clearly defined responsibilities for the prevention of work-related safety, a higher rating of the prevention of work-related accidents, and a higher perceived safety level in the maritime sector. Additionally, several studies also indicate that implementation of SMS is related to positive safety outcomes in the road sector [18-20] and in other sectors [3].

We have, however, seen that there are several differences between the road sector and the transport sectors with SMS requirements, which may represent barriers to SMS implementation in the road sector, including: (1) no international regulatory or standard setting body in road transport of the kind responsible for aviation (ICAO) or maritime transport (IMO); (2) a large share of non-professional road users; (3) many small companies; (4) high proportion of owner-drivers; and (5) low organizational maturity, indicated, e.g., by low degree of reporting of incidents and little systematic focus and follow up of indicators measuring performance [22]. The factors related to small companies and maturity have also been found to be relevant in some subsectors in the maritime sector, where studies indicate poorly adapted SMS and violations of procedures [29,34]. These studies indicate 
that SMS implementation may fail, and that it does not necessarily leads to improved safety culture.

The barriers to SMS implementation in the road sector that were discussed in the ITF [22] roundtable on SMS in transport point to an important paradox: on the one hand, SMS is supposed to contribute to positive safety culture, but if companies have a poor safety culture, they may not be mature enough for successful SMS implementation (and thus improved safety culture). Insufficient organizational maturity, e.g., due to many small companies is listed as a barrier to SMS implementation in the road sector by the ITF [22]. One of the possible solutions to this dilemma, which is suggested in the ITF report, is to implement less comprehensive and simplified SMS in the road sector. This seems to be a fruitful approach, given the barriers to implementation. Nævestad et al. [42] provides such an alternative, which is called the Safety Ladder for safety management. Based on a systematic literature review, taking Norwegian research as its point of departure, Nævestad et al. [42] concludes that four measures seem to be most realistic for small goods-transport businesses, and that these measures seem to have the greatest safety potential. These four measures can be arranged on a ladder, where businesses start at the lowest and most basic level, before proceeding to the next step. The validation and implementation of such simplified SMS approaches is an important issue for future research and policy development.

The third main policy implication of our study is that the responsibility of other parties involved in road transport also should be clarified, e.g., transport buyers, as these also are perceived to have a considerable influence on road safety (cf. [22]).

\section{Conclusions}

The present study supports the assertion that the implementation of rules focusing on the responsibility of road transport companies to prevent work related accidents, by implementing safety management systems (SMS), could lead to increased safety in the road sector. The study indicates that the SMS rules in the maritime sector are related to more clearly defined responsibilities for the prevention of work-related safety. Our study indicates that this in turn is related to a higher rating of the prevention of work-related accidents and a higher perceived safety level in the maritime sector. Additionally, respondents in the maritime sector view SMS as the most important safety measure in the sector in recent years. However, due to barriers to SMS implementation in the road sector, we suggest starting with a simplified version of SMS.

Author Contributions: Conceptualization, T.-O.N. and B.E.; methodology, T.-O.N., B.E., K.R.; formal analysis, T.-O.N., B.E., K.R.; writing-original draft preparation, T.-O.N., B.E., K.R.; writing-review and editing, T.-O.N.; visualization, T.-O.N.; project administration, B.E., T.-O.N.; funding acquisition, T.-O.N., B.E. All authors have read and agreed to the published version of the manuscript.

Funding: The study was financed by the TRANSIKK program of the Research Council of Norway. Grant number 236643.

Institutional Review Board Statement: The study was conducted according to the guidelines of the Declaration of Helsinki, and approved by NSD, Norwegian Centre for Research Data.

Informed Consent Statement: Informed consent was obtained from all subjects involved in the study.

Data Availability Statement: The data presented in this study are available on request from the corresponding author.

Acknowledgments: The study was financed by the TRANSIKK program of the Research Council of Norway, as part of a larger research project "Work-related accidents in road, sea and air transport: Prevalence, causes and measures" (2014-2017). The information described based on the qualitative interviews is based on the situation in 2016-2017, and some of the details may have changed since then. Results from the project are also presented in Elvebakk et al [43].

Conflicts of Interest: The authors declare no conflict of interest. 


\section{References}

1. Nævestad, T.-O.; Phillips, R.O.; Elvebakk, B. Traffic accidents triggered by drivers at work-A survey and analysis of contributing factors. Transportation. Res. Part. F Traffic Psychol. Behav. 2015, 34, 94-107. [CrossRef]

2. Nævestad, T.O.; Phillips, R.; Elvebakk, B.; Bye, R.J.; Antonsen, S. Work-Related Accidents in Norwegian Road, Sea and Air Transport: Prevalence and Risk Factors; TØI Report 1428/2015; Transportøkonomisk Institutt: Oslo, Norway, 2015.

3. Thomas, M.J.W. A Systematic Review of the Effectiveness of Safety Management Systems (No. AR-2011-148); Australian Transport Safety Bureau: Canberra, Australia, 2012.

4. Bernard, B. Safety culture oversight: An intangible concept for tangible issues within nuclear installations. Saf. Sci. 2018, 4, 45 . [CrossRef]

5. ICAO. ICAO Annex 19, Safety Management. Available online: https://www.skybrary.aero/index.php/ICAO_Annex_19, Safety_Management (accessed on 14 March 2021).

6. IATA. Creating a Positive Safety Culture. Best Practices to Align with Annex 19's New Recommendations. Available online: https: / / go.updates.iata.org/safetyculture?_ga=2.26439165.1941341082.1571071913-370565390.1570852392 (accessed on 14 March 2021).

7. Kringen, J. Culture and Control: Regulation of Risk in the Norwegian Petroleum Industry. Ph.D. Thesis, Center for Technology, Innovation and Culture, Faculty of Social Sciences, University of Oslo, Oslo, Norway, 2009.

8. Nævestad, T.-O. Culture, Crises and Campaigns: Examining the Role of Safety Culture in the Management of Hazards in a Highrisk Industry. Ph.D. Thesis, University of Oslo, Oslo, Norway, 2010.

9. IMO. 2018: ISM Code. International Safety Management Code with Guidelines for Its Implementation; IMO: London, UK, 2018.

10. European Rail Agency. Available online: https://www.era.europa.eu/activities/safety-management-system_en (accessed on 14 March 2021).

11. Nævestad, T.-O.; Hesjevoll, I.S.; Ranestad, K.; Antonsen, S. Strategies regulatory authorities can use to influence safety culture in organizations: Lessons based on experiences from three sectors. Saf. Sci. 2019, 118, 409-423. [CrossRef]

12. Adjekum, D.K.; Tous, M.F. Assessing the relationship between organizational management factors and a resilient safety culture in a collegiate aviation program with Safety Management Systems (SMS). Saf. Sci. 2020, 131, 104909. [CrossRef]

13. Lappalainen, F.J.; Kuronen, J.; Tapaninen, U. Evaluation of the ISM Code in the Finnish shipping companies. J. Marit. Res. 2012, 9, 23-32.

14. Amtrak. Safety and Security: Opportunities Exist to Improve the Safe-2-Safer Program, Audit Report OIG-A-2015-007; Amtrak: Washington, DC, USA, 2015.

15. Zuschlag, M.; Ranney, J.M.; Coplen, M. Evaluation of a safety culture intervention for Union Pacific shows improved safety and safety culture. Saf. Sci. 2016, 83, 59-73. [CrossRef]

16. Phillips, R.O.; Nævestad, T.-O.; Jordbakke, G. Increasing the Implementation of Traffic Safety Management Systems by Organisations, TØI Report 1664/2018; TØI: Oslo, Norway, 2018.

17. Naveh, E.; Katz-Navon, T. A longitudinal study of an intervention to improve road safety climate: Climate as an organizational boundary spanner. J. Appl. Psychol. 2015, 100, 216-226. [CrossRef] [PubMed]

18. Murray, W.; Ison, S.; Gallemore, P.; Nijjar, H.S. Effective occupational road safety programs a case study of Wolseley. Transp. Res. Rec. J. Transp. Res. Board 2009, 2096, 55-64. [CrossRef]

19. Murray, W.; White, J.; Ison, S. Work-related road safety: A case study of Roche Australia. Saf. Sci. 2012, 50, 129-137. [CrossRef]

20. Wallington, D.; Murray, W.; Darby, P.; Raeside, R.; Ison, S. Work-related road safety: Case study of British telecommunications (BT). Transp. Policy 2014, 32, 194-202. [CrossRef]

21. Elvik, R.; Vaa, T.; Erke, A.; Sorensen, M. The Handbook of Road Safety Measures; Emerald Group: Oslo, Norway, 2009.

22. ITF. Safety Management Systems. Summary Report of rountable meeting held at OECD headquarters on 23-24 March 2017. In ITF/TRC (2017)21; ITF: London, UK, 2017.

23. Nævestad, T.-O.; Phillips, R.O. Trafikkulykker ved Kjøring i Arbeid—En Kartlegging og Analyse av Medvirkende Faktorer, TØI Rapport 1269/2013; Transportøkonomisk Institutt: Oslo, Norway, 2013.

24. Newnam, S.; Watson, B. Work-related driving safety in light vehicle fleets: A review of past research and the development of an intervention framework. Saf. Sci. 2011, 49, 369-381. [CrossRef]

25. NOU 1999: 30-Regjeringen. No. Available online: https://www.regjeringen.no/no/dokumenter/nou-1999-30/id142198/?ch= 15 (accessed on 14 March 2021).

26. Størkersen, K.V.; Thorvaldsen, T. Traps and Tricks of Safety Management at Sea. Saf. Sci. 2021, 134, 105081. [CrossRef]

27. SSA. Norwegian Ship Safety Act. Available online: https://lovdata.no/dokument/NL/lov/2007-02-16-9 (accessed on 14 March 2021).

28. Elvebakk, B. Between Control. and Collaboration: Transport. Safety Inspectorates in Norway, TØI Report 1404/2015; Institute of Transport Economics: Oslo, Norway, 2015.

29. Bjørnskau, T.; Longva, F. Sikkerhetskultur i Transport; TØI Rapport 1012/2009; Transportøkonomisk Institutt: Oslo, Norway, 2009.

30. Nævestad, T.-O.; Phillips, R.O. The Relevance of Safety Culture as a Regulatory Concept and Management Strategy in Professional Transport.: Comparing the Experiences of Regulators and Companies from Four Sectors; TØI Rapport 1668/2018; Transportøkonomisk Institutt: Oslo, Norway, 2018.

31. Hudson, P. Applying the lessons of high risk industries to health care. BMJ Qual. Saf. 2003, 12, i7-i12. [CrossRef] [PubMed] 
32. Patankar, M.S. Chapter 13-Maintenance Resource Management for Technical Operations. In Crew Resource Management, 3rd ed.; Kanki, B.G., Anca, J., Chidester, T.R., Eds.; Elsevier: Amsterdam, The Netherlands, 2019; pp. 357-405.

33. Antonsen, S. The relationship between culture and safety on offshore supply vessels. Saf. Sci. 2009, 47, 1118-1128. [CrossRef]

34. Bye, R.J.; Aalberg, A.L. Why do they violate the procedures?-An exploratory study within the maritime transportation industry. Saf. Sci. 2020, 123, 104538. [CrossRef]

35. Nævestad, T.-O.; Phillips, R.; Levlin, G.M.; Hovi, I.B. Internationalisation in Road Transport of Goods in Norway: Safety Outcomes, Risk Factors and Policy Implications. Safety 2017, 3, 22. [CrossRef]

36. Mooren, L.; Grzebieta, R.; Williamson, A.; Olivier, J.; Friswell, R. Safety management for heavy vehicle transport: A review of the literature. Saf. Sci. 2014, 62, 79-89. [CrossRef]

37. Reason, J. Managing the Risk of Organisational Accidents; Ashgate: Aldershot, UK, 1997.

38. RTA. Norwegian Road Traffic Act. Available online: https:/ lovdata.no/dokument/NL/lov/1965-06-18-4 (accessed on 14 February 2021).

39. WEA. Norwegian Working Environment Act. Available online: https:/ lovdata.no/dokument/NL/lov/2005-06-17-62 (accessed on 14 March 2021).

40. Gregersen, N.P.; Brehmer, B.; Morén, B. Road safety improvement in large companies. An experimental comparison of different measures Accident Analysis. Prevention 1996, 28, 297-306.

41. Nævestad, T.-O.; Phillips, R.O.; Hovi, I.B.; Elvik, G.N.J. Miniscenario: Sikkerhetsstigen. In Innføre tiltak for Sikkerhetsstyring $i$ Godstransportbedrifter. TØI Rapport 1620/2018; Transportøkonomisk Institutt: Oslo, Norway, 2018.

42. Nævestad, T.O.; Phillips, R.O.; Elvebakk, B. The safety ladder: Developing an evidence-based safety management strategy for small road transport companies. Transp. Rev. 2018, 38, 372-393. [CrossRef]

43. Elvebakk, B.; Nævestad, T.-O.; Ranestad, K. Work-Related Accidents in Norwegian Road, Sea and Air Transport. Roles and Responsibilities; TØI Report 1567/2017; TØI: Oslo, Norway, 2017. 